\title{
ANALYSIS OF THE DIFFERENCE OF COMPLETENESS OF REPORTING AND DOCUMENTATION OF LABORATORY CRITICAL VALUES PRE AND POST-INTERVENTION IN BONA WARD Dr. SOETOMO HOSPITAL SURABAYA
}

\author{
Zubir $^{1}$, Hartono Kahar ${ }^{1}$, M. Robiul Fuadi ${ }^{1}$, Elly Sulistyani ${ }^{2}$, Tito Yustiawan ${ }^{3}$ \\ ${ }^{1}$ Department of Clinical Pathology, Faculty of Medicine, Airlangga University-Dr.Soetomo Hospital Surabaya, Indonesia. E-mail: \\ dr.zubiribrahim@gmail.com \\ Committee of Patient Safety and Quality, Dr.Soetomo Hospital Surabaya, Indonesia \\ 3 Department of Health Policy and Administration, Faculty of Public Health, Airlangga University
}

\begin{abstract}
Completeness of reporting and documentation of laboratory critical values in medical records is important for patient safety, hospital accreditation, and legality. Preliminary study in the Dr. Soetomo Hospital ward showed that the laboratory critical value report and documentation was $0 \%$ complete, $4 \%$ incomplete, and $96 \%$ undocumented. This was a quasi-experimental study with one group pretest and posttest design. Technical guidance of reporting and documentation of laboratory critical values in medical records and supervision was given to 26 doctors. The results evaluated were doctor's knowledge and attitude towards critical value reporting, completeness of documentation in medical records, and Turnaround Time (TAT). The number of reporting critical values samples was 72 before and after the intervention. The critical value samples were taken by purposive sampling. The data were analyzed using the Mann-Whitney test. There were significant differences in the level of knowledge, doctor's attitudes, and completeness of critical values documentation before and after the intervention. Doctors with good knowledge increased from $3.85 \%$ to $92.31 \%$. The attitude to complete critical values documentation improved from $0 \%$ to $76 \%$. Completeness of critical values documentation in medical records improved from $100 \%$ undocumented to $19.44 \%$ undocumented, $11.11 \%$ incomplete, and $69.45 \%$ complete. There were no significant differences of TAT before and after the intervention, all the TAT was less than 30 minutes and met the TAT requirement. The intervention was able to increase doctor knowledge, attitude, and completeness of the laboratory critical values reporting and documentation in the patient's medical record.
\end{abstract}

Key words: Laboratory critical value, medical record, turn around time

\section{INTRODUCTION}

Patient safety is the main focus of hospital and health services. ${ }^{1}$ One of the goals of patient safety is to improve effective communication in terms of laboratory critical value reporting. ${ }^{2}$ World Health Organization (WHO) report on patient safety in 2008 revealed poor follow-up to the critical value (critical value did not reach the clinician, or the patient got late treatment) as the main cause of harm to the patient. ${ }^{3}$ The critical value of the laboratory is the abnormal value and striking laboratory tests result that can endanger the patient's life if immediate treatment is not carried out. Submitting critical values correctly by the laboratory to the clinician/ward will determine the proper and fast management to provide good outcomes. Conversely, poor communication can endanger the lives of patients. ${ }^{4}$
The initial research was conducted in September 2017 for four days with a total sample of 74 critical values reports from 10 wards with details as follows: $0 \%$ complete, $4 \%$ incomplete, and $96 \%$ totally undocumented. Primary data from the laboratory critical report book of Clinical Pathology Laboratory in the Integrated Diagnostic Center Building Dr. Soetomo Hospital in December 2017 showed that the highest number of critical values reports was from the Bona 2 Pediatric Ward (12.5\%) with the highest number of recipients were nurses $(70 \%)$, doctors (28\%) and the remaining $2 \%$ was internship students and nutritionists. ${ }^{5}$

Until now the process of submitting laboratory critical value reports and documentation processes to the doctor in charge of the patient ward is unknown and has never been evaluated. Submitting reports of critical values to the clinician properly is an important point because it determines patient 
safety. Documentation of critical value reports as authentic evidence of reporting by the laboratory staff should be clear and completely recorded on the patient's medical record. Completeness of documentation data is very important because reporting critical values is not only important from the clinical but also from the legal aspect. ${ }^{4}$

This study intervened in the form of technical guidance and supervision on how to correctly receive reports and documentation of laboratory critical values in the Bona Pediatric Ward and analyzed differences in the level of completeness of documentation and reporting of laboratory critical values before and after the intervention. This research was expected to improve patient safety at the Dr. Soetomo Hospital Surabaya.

\section{METHODS}

The study was conducted from April 1 to May 13, 2018, with a quasi-experimental design and one group pretest and posttest type samples were taken by purposive sampling. The study samples consisted of 26 doctors and 72 reporting of laboratory critical values before and after the intervention. The parameters measured were the level of knowledge, attitude, completeness of data documentation and critical values, and TAT. The level of doctor's knowledge of critical values was measured before and after the intervention using instruments in the form of 10 multiple choice questions that had been previously validated and the results were then classified into good, medium, and bad categories. The doctor's attitude towards critical values was measured based on his/her reaction to do complete documentation when receiving critical value reporting and the results were categorized into good, medium, and bad. Complete documentation of critical value reporting was measured based on the completeness of critical value reporting data in the patient's medical record consisting of; D1: The patient's identity (name and medical record number), D2: Date and time of reporting, D3: The name of the laboratory doctor who reported it, D4: Name of report recipient, and D5: Critical value reported (test name and value). The completeness of documentation data was classified into a complete, incomplete and undocumented category. TAT was counted based on the length of time since the test results were found with a critical value until it was reported to the ward and then the results were classified into a meeting or not meeting the TAT with a maximum time limit of 30 minutes. The data were then processed using a computer-based statistical data processing program.

The intervention was technical guidance and supervision. The technical guidance was a presentation about laboratory critical values and group discussion to the Bona Pediatric Ward doctors. Supervision was checking the completeness of critical value reporting and documentation data at patient's medical record every day at the postintervention phase with input and acceptance of advice from doctors in the ward (if there was any). The implementation of supervision was not only carried out through face-to-face meetings with doctors but also through online communication media groups to socialize the results of supervision every day to all Bona Pediatric Ward doctors.

All data obtained were tested for normality using Kolmogorov-Smirnov and then different tests were carried out. Normally distributed data were tested using a t-test while for abnormally distributed data the Mann-Whitney test with a significant value of 0.05 was used Ethical clearance was obtained from The Ethics Committee of Health Study of Dr. Soetomo Hospital Surabaya with registration number 0180/KEPK//IV/2018.

\section{RESULTS AND DISCUSSION}

The results showed significant differences in the level of knowledge of critical values, attitude of doctors, and complete documentation of critical values before and after the intervention, while TAT of critical values reporting did not show significant differences.

The level of knowledge of doctors in the Bona Pediatric Ward for critical values before the intervention was generally low among 26 respondents with an average value of 2656.92 . The doctor's knowledge of critical values in the postintervention phase increased significantly with a mean value of 86.54 . The difference in pre-intervention and post-intervention knowledge was significantly different with $p<0.05$. The

Table 1. Differences in the level of doctor's knowledge of the critical values in pre-intervention and post-intervention phases

\begin{tabular}{cccccc}
\hline Knowledge & (n) & Minimum & Maximum & Average \pm SD & p \\
\hline Pretest & 26 & 30 & 80 & $56.92 \pm 11.582$ & 0.001 \\
Posttest & 26 & 70 & 100 & $86.54 \pm 8.458$ & \\
\hline
\end{tabular}


differences in the level of a doctor's knowledge of critical value before and after the intervention can be seen in Table 1.

Comparison of the level of doctor's knowledge in the pre-intervention and post-intervention phases was obtained after conversion of the values obtained by each respondent into the knowledge level category as shown in Table 2.

Table 2. Comparison of the level of knowledge of physicians in the Bona Pediatric Ward to the critical values of pre-intervention and post-intervention

\begin{tabular}{lccc}
\hline & \multicolumn{3}{c}{ Knowledge Level (\%) } \\
\cline { 2 - 4 } Group & Good & Medium & Poor \\
\hline & $>80$ & $65-79$ & $<65$ \\
Pretest & 3.85 & 15.39 & 80.76 \\
Posttest & 92.31 & 7.69 & 0.00 \\
\hline
\end{tabular}

The level of knowledge of pre-intervention respondents was generally poor (80.76\%) and after the intervention changed drastically to good (92.31\%) and there were no respondents with a poor level of knowledge. Based on Table 2, it could be concluded that the intervention in technical guidance and supervision had succeeded in increasing the level of knowledge.

Good knowledge of critical values was expected to improve the quality of critical value documentation in the patient's medical record. This was in accordance with research conducted by
Nuryani and Susanti in Dr. Soekardjo Hospital, the city of Tasikmalaya in 2013 which showed a significant correlation between the level of knowledge of officers and the completeness of medical record documents. Officers with good knowledge would fill in medical record documents better and more complete, while officers with poor knowledge tended to fill in documents incompletely. ${ }^{6}$ Other studies with similar results to this study were carried out by Ardika which showed a meaningful correlation between knowledge of officers with complete medical record documents in his research at the Dr. Kariadi Hospital Semarang. ${ }^{7}$

The number of critical values reports received by the group of doctors increased from $55.56 \%$ in the pre-intervention phase to $91.67 \%$ in the post-intervention phase. Increased acceptance of reports by doctors was also followed by increased complete documents from $0 \%$ in the pre-intervention phase to $69.45 \%$ in the post-intervention phase. Doctors' attitudes to complete document critical values also increased from $0 \%$ at pre-intervention to $75.76 \%$ postintervention. Distribution of critical value reports recipients, completeness of documentation data at medical records, and an overview of the attitudes of doctors in the Bona pediatric ward to critical values reports on pre-intervention and post-intervention can be seen in Table 3.

The results showed a decreased number of doctors who did not record critical values from $100 \%$ in the pre-intervention phase to only $12 \%$ in the

Table 3a. Distribution of recipients and completeness of critical report documents in the Bona Ward at pre-intervention

\begin{tabular}{lcccc}
\hline & \multicolumn{4}{c}{ Pre-intervention: Completeness of Documentation Data (\%) } \\
\cline { 2 - 5 } Report Recipients & Complete & Incomplete & Undocumented & Total \\
\hline Doctor & 0 & 0 & 55.56 & 55.56 \\
Non doctor & 0 & 0 & 44.44 & 44.44 \\
Total & $\mathbf{0}$ & $\mathbf{0}$ & $\mathbf{1 0 0}$ & $\mathbf{1 0 0}$ \\
\hline
\end{tabular}

Table 3b. An overview of the doctor's attitude in the Bona ward towards critical values reporting at pre-intervention

\begin{tabular}{lcccc}
\hline Classification of Critical Value Data & \multirow{2}{*}{$\begin{array}{c}\text { Attitude } \\
\text { Scale }\end{array}$} & $\begin{array}{c}\text { Attitude } \\
\text { Category }\end{array}$ & \multicolumn{2}{c}{ Pre-Intervention } \\
\cline { 5 - 6 } & 2 & Good & 0 & (n) \\
\hline Complete $(5$ out of 5$)$ & 1 & Medium & 0 & 0 \\
Incomplete $(1$ to 4 of 5$)$ & 0 & Bad & 20 & 100 \\
Undocumented (0 out of 5) & & & $\mathbf{2 0}$ & $\mathbf{1 0 0}$ \\
Total & &
\end{tabular}


Table 3c Distribution of recipients and completeness of critical report documents in the Bona Ward at post-intervention

\begin{tabular}{lcccc}
\hline & \multicolumn{3}{c}{ Post-Intervention: Completeness of Documentation Data (\%) } \\
\cline { 2 - 5 } Report Recipients & Complete & Incomplete & Undocumented & Total \\
\hline Doctor & 69.45 & 11.11 & 11.11 & 91.67 \\
Non doctor & 0 & 0 & 8.33 & 8.33 \\
Total & $\mathbf{6 9 . 4 5}$ & $\mathbf{1 1 . 1 1}$ & $\mathbf{1 9 . 4 4}$ & $\mathbf{1 0 0}$ \\
\hline
\end{tabular}

Table 3d. An overview of the doctor's attitude in the Bona ward towards critical values reporting at post-intervention

\begin{tabular}{lcccc}
\hline Classification of Critical Value Data & Attitude & \multirow{2}{*}{$\begin{array}{c}\text { Attitude } \\
\text { Socale }\end{array}$} & \multicolumn{2}{c}{ Post-Intervention } \\
\cline { 5 - 6 } & Category & (n) & (\%) \\
\hline Complete $(5$ out of 5$)$ & 2 & Good & 25 & 75.76 \\
Incomplete $(1$ to 4 of 5$)$ & 1 & Medium & 4 & 12.12 \\
Undocumented (0 out of 5) & 0 & Bad & 4 & 12.12 \\
Total & & & $\mathbf{3 3}$ & $\mathbf{1 0 0}$ \\
\hline
\end{tabular}

Table 4. Attitudes in documenting the reporting of critical values by doctors and non-doctors at patient's medical records at pre-intervention and post-intervention phase

\begin{tabular}{lccccc}
\hline Attitude & $(\mathbf{n})$ & Minimum & Maximum & Average \pm SD & p (<0.05) \\
\hline Pre-intervention & 36 & 0 & 0 & $0.00 \pm 0.000$ & 0.001 \\
Post-intervention & 36 & 0 & 2 & $1.50 \pm 0.811$ & \\
\hline
\end{tabular}

Note: attitude scale $0=$ did not do documentation, $1=$ did documentation but not complete, $2=$ complete documentation

postintervention phase. The decreased number of doctors who did not record critical values was also followed by an increased number of doctors who completely recorded critical values from $0 \%$ to $76 \%$.

The difference in attitudes of doctors as recipients of reports in the Bona ward in documenting the critical value of the patient's medical record at the pre-intervention and post-intervention in this study was then statistically analyzed to determine the significance.

Table 4 showed the average attitude of doctors towards reporting critical values. There was an improved attitude of the doctors who did not document the reporting of critical values at medical records in the pre-intervention phase (mean 0.00 ) to attitude average of 1.5 with scale 2 attitude as the maximum score. This attitude change was statistically significant with a $p$-value $<0.05$.

Based on the explanation, it could be interpreted that the intervention in the aspect of technical guidance and supervision improved the attitude of the research subject to the reporting of critical values on the patient's medical records.

Improvements in doctors' attitudes towards reporting critical values should also be followed by quality improvements of documentation of reporting critical values in the patient's medical records. The complete distribution of documentation data for reporting laboratory critical values during the study can be seen in Table 5 .

Table 5 showed the distribution of completeness of data documentation of laboratory critical values in the Bona Pediatric Ward during the study. Completeness of data documentation in the pre-intervention phase was very poor because none of the critical value reporting data to the Bona ward (D1 to D5) was recorded in the laboratory archives of the Clinical Pathology Laboratory. Completeness of post-intervention data has changed for the better with 25 documents classified as complete even though there were still undocumented documents (seven documents). The difference in the completeness of the documentation data for critical values reporting in pre-intervention and post-intervention phases was then analyzed to determine the statistical significance.

Table 6 showed the differences of the completeness level of critical value documentation data of patient's medical records during the pre-intervention and post-intervention phase. Based on Table 6 it was 
known that the average document completeness had increased from scale 0 in the pre-intervention phase to 3.83 in the post-intervention phase with a maximum scale of 5 . After analysis using the Mann-Whitney test, a significant difference was obtained with a $p$-value of $<0.05$. The conclusion that could be taken based on Table 6 was the provision of interventions as technical guidance and supervision of reporting and documentation of laboratory critical values had succeeded in increasing the completeness of laboratory critical value documentation data at the patient's medical record.

Technical guidance for medical personnel was needed to increase awareness and improved the attitude of medical personnel to the critical value of the laboratory and improved the quality of documentation of the patient's medical record. Other studies regarding technical guidance and completeness of medical record data that gave similar results to this study were conducted by Tola et al. Tola et al. conducted an intervention in medical record documentation training for medical personnel in hospitals in Ethiopia and showed an increased completeness of medical record data from $73 \%$ before intervention to $84 \%$ after intervention. ${ }^{8}$
Different results were obtained by Payage at the Dekai Papua and Mastini at the Sanglah Hospital in Bali. Both studies did not find a relationship between the knowledge of officers and the completeness level of the documents, but the two studies mentioned that the level of knowledge of the officers in the studies was in a good category, suggesting a contrast conditions with this study.,10

The results of this study as a whole had improved the attitude of doctors in the Bona Pediatric Ward to reporting critical laboratory values and documentation of laboratory critical value reporting at patient's medical records by doctors to be better (complete category $69.45 \%$, incomplete $11.11 \%$, no documented $11.11 \%$ ).

The mean TAT reporting of critical values by laboratory officers to the ward during the study can be seen in Table 7.

Based on Table 7, it was found that the mean value of post-intervention TAT (4.94 minutes) was better than the pre-intervention (5.35 minutes) although the longest TAT in this study (20 minutes) was obtained in the postintervention phase. Turnaround time of critical values reporting from the Clinical Pathology Laboratory to the Bona Ward both

Table 5. Completeness of documentation data on laboratory critical value reporting of patient's medical records during pre-intervention and post-intervention phase

\begin{tabular}{|c|c|c|c|c|c|c|c|c|c|c|c|c|}
\hline \multirow{2}{*}{$\frac{\text { Study Phase }}{\text { Data completeness }}$} & \multicolumn{5}{|c|}{ Pre-Intervention } & \multirow{2}{*}{ (n) } & \multicolumn{5}{|c|}{ Post-Intervention } & \multirow{2}{*}{ (n) } \\
\hline & $\mathrm{D} 1$ & D2 & D3 & D4 & D5 & & D1 & D2 & D3 & D4 & D5 & \\
\hline Complete & - & - & - & - & - & 0 & $\mathrm{v}$ & $\mathrm{v}$ & $\mathrm{v}$ & $\mathrm{V}$ & $\mathrm{v}$ & 25 \\
\hline \multirow[t]{3}{*}{ Incomplete } & - & - & - & - & - & 0 & - & - & $\mathrm{v}$ & V & - & 1 \\
\hline & & & & & & & - & - & $\mathrm{v}$ & V & $\mathrm{v}$ & 1 \\
\hline & & & & & & & $\mathrm{v}$ & $\mathrm{v}$ & $\mathrm{v}$ & - & $\mathrm{v}$ & 2 \\
\hline Undocumented & - & - & - & - & - & 36 & - & - & - & - & - & 7 \\
\hline Total & & & & & & 36 & & & & & & 36 \\
\hline
\end{tabular}

Table 6. Mean differences in the completeness of documentation of critical values of patient's medical record during pre-intervention and post-intervention

\begin{tabular}{lccccc}
\hline Data Completeness & $(\mathbf{n})$ & Minimum & Maximum & Average \pm SD & $\mathbf{p ~ ( < 0 . 0 5 )}$ \\
\hline Pre-intervention & 36 & 0 & 0 & $0.00 \pm 0.000$ & 0.001 \\
Post-intervention & 36 & 0 & 5 & $3.83 \pm 2.007$ & \\
\hline
\end{tabular}

Table 7. Mean differences of TAT reporting of critical values of patient's medical records during pre-intervention and post-intervention phase

\begin{tabular}{lccccc}
\hline & (n) & Minimum & Maximum & Average \pm SD & p (<0.05) \\
\hline Pre-intervention TAT & 34 & 1 & 15 & $5.35 \pm 3.667$ & 0.301 \\
Post-intervention TAT & 36 & 1 & 20 & $4.94 \pm 4.381$ & \\
\hline
\end{tabular}


before and after the intervention were not significantly different $(p>0.05)$. TAT in this study was counted from the critical value found by the laboratory staff to be reported to the clinician in the ward according to the TAT definition of the laboratory critical value set at the Dr. Soetomo Hospital Surabaya.

Turnaround time values in this study were better than the results of a study conducted by Fei et al. in 937 laboratories in China. This study showed an average TAT of 25 minutes. ${ }^{11}$ Research conducted by Agarwal, Chillar, and Tripathi in India showed TAT values ranging from 30-120 minutes. The TAT values in Agarwal, Chillar, and Tripathi's study were significantly different from the average TAT obtained in this study. The difference of TAT values between the two studies was due to differences in the definition of TAT used. Agarwal, Chillar, and Tripathi used the TAT limitation critical value as the time counted from sample received until the critical results were conveyed to the clinician. ${ }^{12}$

From the findings and discussion of the technical guidance activities, it was revealed that none of the Bona ward doctors had received materials about critical values, even though the knowledge was closely related to the ability and attitudes of doctors in documenting critical values in medical records. Most participants of technical guidance did not know the medical record page for critical value documentation, and none of them knew the standards operational procedure of critical value reporting including how to record and report laboratory critical values. These were proved by the poor level of knowledge, attitude, and complete documentation of critical values in the pre-intervention phase. Another important fact that was discovered during the discussion was that doctors often did not know an incoming call for reporting critical values because they were in a ward examining patients. The results of the discussion recommended the use of cellular phones for reporting critical values by the hospital.

Technical guidance as done in this study was needed so health officers could make medical documents with good quality. Castledine stated that incomprehensive documentation was one of the problems because it was less effective. Therefore, guidance to make medical records was required. ${ }^{13}$

The use of a mobile communication system for doctors in the ward was also expected to simplify and shorten the flow of critical value delivery to the doctor. In addition to its ability to ensure critical results information to the doctor, the use of mobile communication devices by doctors in the ward connected to laboratory staff and the Laboratory Information System (LIS) was also able to reduce errors in reporting critical values. ${ }^{14}$ Other studies conducted by Park et al. about evaluation of the use of Short Message Service (SMS) along with the telephone to mobile communication instruments for reporting critical values, it was shown that the results of actions taken by clinicians became faster and patient care became better. ${ }^{15}$

In the initial period of supervision, there were still undocumented reporting of critical values. Based on the results of supervision, it was revealed that doctors in the ward claimed to forget and were not used to it. Generally, the doctor of the ward was very supportive of this research by willing to produce a documentation stamp of critical results to facilitate the documentation of critical value reporting in the medical record. The mid and final period of supervision of the documentation of critical values in the medical record was remarkably improved.

Supervision in this research was done directly to the doctor who was on duty in the ward and indirectly to all doctors through the electronic communication group. The provision of intervention through electronic communication groups enabled mobile learning for all doctors and strengthened supervision activities for health workers as found in this study. Another study on the use of electronic communication groups was conducted by Henry et al. in 2016. The study used the WhatsApp application to strengthen supervision of health workers in Kenya and it was proved that the application was able to direct health workers to act according to the target goals. ${ }^{16}$

\section{CONCLUSION AND SUGGESTION}

There were significant differences in the level of knowledge of critical values, attitudes of doctors, completeness of documentation of critical values before and after the intervention. Contrarily, there were no significant differences in TAT reporting of critical values. Technical guidance for reporting and documentation of critical values according to standard operating procedures for new doctors must be carried out routinely before serving in the Dr. Soetomo Hospital Surabaya. The use of cell phones for reporting critical laboratory values to doctors needs to be reconsidered because they are related to patient safety. Supervision must also be continued by the committee of quality improvement and patient safety of the Dr. Soetomo Hospital 
Surabaya as part of the controlling function for patient safety.

\section{REFERENCES}

1. Al-etreby W, Al-harthy A, Karim S, Al-jabri M, Dumlao $\mathrm{LA}$, et al. Impact of improved critical lab results documentation on patient's safety, a prospective study. International Journal of Health Sciences and Research. 2015; 5(9): 67-71.

2. Wibowo B, Sutarjo US, Pranawa, Supriyatno B, Purjanto KA, et al. Standar Nasional Akreditasi Rumah Sakit, $1^{\text {st }}$ Ed., Jakarta, Komisi Akreditasi Rumah Sakit. 2017; 46-48.

3. The Royal College of Pathologists of Australasia, The Australasian Association of Clinical Biochemists. Guideline consensus statement for the management and communication of high-risk laboratory results. The Royal College of Pathologists of Australia, Australia, 2017; 1/2015: 1-17.

4. Yang D, Zhou Y, Yang C. Analysis of laboratory repeat critical values at a large tertiary teaching hospital in China. PLoS ONE, 2013; 8(3): 11-14.

5. RSUD Dr. Soetomo. Buku laporan nilai kritis. 2017.

6. Nuryani N, Susanti DD. Hubungan pengetahuan perawat dengan kelengkapan dokumentasi asuhan keperawatan di RSUD Dr. Soekardjo kota Tasikmalaya. Manajemen Informasi Kesehatan Indonesia, 2014; 2(2): 5-9.

7. Ardika RG. Hubungan antara pengetahuan perawat tentang rekam medis dengan kelengkapan pengisian catatan keperawatan. Semarang, Program Pendidikan Sarjana Kedokteran Fakultas Kedokteran Universitas Diponegoro, 2012; 47-49.

8. Tola K, Abebe H, Gebremariam Y, Jikamo B. Improving completeness of inpatient medical records in Menelik II Referral Hospital, Addis Ababa, Ethiopia. Advances in Public Health, 2017; 201: 1-5.
9. Payage J, Rantetampang AL, Sandjaja B, Mallongi A. Factors affecting performance of nurse to medical record documentation caregiver health care at Dekai Regional Public Hospital Papuan Province. International Journal of Scientific Progress and Research, 2018; 44(126): 13-21.

10. Mastini, P. Pengaruh pengetahuan, sikap, beban kerja dengan pendokumentasian asuhan keperawatan IRNA di Rumah Sakit Umum Pusat Sanglah Denpasar. Program magister program studi ilmu kesehatan masyarakat program pascasarjana Universitas Udayana, Denpasar. 2013; 63-66

11. Fei $Y$, Zhao H, Wang W, He F, Zhong $K$, et al. National survey on current situation of critical value reporting in 973 laboratories in China. Biochem Med, Zagreb, 2017; 27(3): 1-10.

12. Agarwal R, Chillar N, Tripathi CB. Study of variables affecting critical value notification in a laboratory catering to tertiary care hospital. Ind J Clin Biochem, 2015; 30(1): 89-93.

13. Castledine G. The importance of nursing documentation. British Journal of Community Health Nursing, 1997; 2(8): 372.

14. Parl FF, O'Leary MF, Kaiser AB, Paulett JM, Statnikova K, et al. Implementation of a closed-loop reporting system for critical values and clinical communication in compliance with goals of the joint commission. Clinical Chemistry, 2010; 56(3): 417-23.

15. Chung HJ, Lee W, Chun S, Park H Il, Min WK. Analysis of turn around time by subdividing three phases for outpatient chemistry specimens. Annals of Clinical and Laboratory Science, 2009; 39(2): 144-49.

16. Henry JV, Winters N, Lakati A, Oliver M, Geniets A, et al. Enhancing the supervision of community health workers with WhatsApp Mobile Messaging: Qualitative findings from 2 low-resource settings in Kenya. Global Health: Science and Practice, 2016; 4(2): 311-25. 